\title{
Adsorption of Methylene Blue onto Chemically Prepared Activated Carbon from Date Palm Pits: Kinetics and Thermodynamics
}

\author{
A. M. Youssef ${ }^{2}$, H. EL-Didamony ${ }^{3}$, M. Sobhy ${ }^{1, a^{*}}$, S. F. EL- Sharabasy ${ }^{1, b}$ \\ ${ }^{1}$ Central Laboratory of Date Palm Research and Development, Agricultural Research Center, \\ Egypt \\ ${ }^{2}$ Department of Chemistry, Faculty of Science, Mansoura University, Mansoura, Egypt \\ ${ }^{3}$ Department of Chemistry, Faculty of Science, Zagazig University, Zagazig, Egypt \\ E-mail: mahasobhy1000@yhaoo.com
}

Keywords: date palm pits activated carbon, methylene blue, kinetics, thermodynamics

\begin{abstract}
Three activated carbons were prepared using phosphoric acid (P) as an activating agent from date palm pits (DPP) as a precursor via thermal pretreatment producing (CP212, CP214 and CP124) samples, where the ratio of raw material to phosphoric acid is (2:1and 1:2) respectively at curing time two days for first sample and four days for the second and third sample, the activating temperature was $550^{\circ} \mathrm{C}$, the precursor was washed with distilled water, dried, crushed, and then sieved. In order to study the effect of phosphoric acid modification, the characteristics of the activated carbon produced were determined before and after acid modification and subsequently compared. These characteristics include surface morphology, surface area, average pore diameter and pore volume. Characterization results showed that modification of date palm pits with phosphoric acid enhanced the surface area of the activated carbon from 427.8 to620.3 m²/g. The average pore diameter was also enhanced from 1.14 to 1.82 $\mathrm{nm}$. SEM analysis confirmed the improvement in surface area and pore development resulting from the phosphoric acid modification.
\end{abstract}

\section{Introduction}

$\mathrm{MB}$ is synthetic thiazine dye of an amorphous nature with a molecular formula $\mathrm{C}_{16} \mathrm{H}_{18} \mathrm{ClN}_{3} \mathrm{~S} . \mathrm{xH}_{2} \mathrm{O}$. It is also called basic blue, tetra methylthionine chloride and colour index (Cl) number 52012. The molecular weight of MB is 320 and its maximum wave length 662nm. It is dark green powder, with a characteristic deep blue colour in aqueous solution where it dissociates into an MB cation and a chloride anion dye, Methylene blue is a common dye mostly used by industries involve in textile, rubber, paper, plastics, leather, pharmaceutical cosmetics, and food industries. Effluents discharged from such industries contain residues of dyes. Consequently, the presence of very low concentrations in effluent is highly visible $[1,2]$. Discharge of colored waste water without proper treatment can results in numerous problems such as chemical oxygen demand (COD) by the water body, and an increase in toxicity. Organic dyes are harmful to human beings the need to remove color from waste water become environmentally important. It is rather difficult to treat dye effluents because of their synthetic origins and mainly aromatic structures, which are biologically non-degradable. Moreover, their degradation products may be mutagenic and carcinogenic [3,4]. Many dyes may cause allergic dermatitis, skin irritation, and dyes function of kidney, liver, and brain, reproductive and central nervous system [5]. It is estimated that $10-15 \%$ of the dyes are lost in the effluent during the dyeing processes. Activated carbon has been extensively used in wastewater treatment, chemical 
recovery and catalytic support industries primarily due to large surface area and presence of different pore sizes [6]. In most reported cases chemical activation is preferred as it, getting better porous, more surface area and high yielding activated carbons [7]. Date palm pits are considered one of the most useful and an abundant renewable agricultural waste, in 2006 world production of dates, was about 7 million tons. About $14 \%$ of the fruit is waste material, in the form of seeds. Date stones represent about $10 \%$ of the date weight. The chemical composition of date stone consists of hemicelluloses (23\%), lignin (15\%), and cellulose (57\%) [8]. Date palm pits is not consumable by humans in any form; it has a high content of crude fiber (around 19\%) that may cause digestibility problems in ruminant animals as well The main objective of this research is to prepare phosphoric acid $\left(\mathrm{H}_{3} \mathrm{PO}_{4}\right)$-activated carbons from date palm pits.

The following methods were used to characterize the prepared activated carbons: nitrogen adsorption at $-196^{\circ} \mathrm{C}$, scanning electron microscopy for analysis of the surface chemistry, pHpzc, surface $\mathrm{pH}$ analysis, and measurement of $\mathrm{MB}$ adsorption capacity at different temperatures. Special attention was paid to kinetic studies.

\section{Materials and Methods}

\section{Materials}

All the primary chemicals used in this study were of analytical grade. Methylene blue with 99.99\% purity was obtained from Sigma-Aldrich Company and phosphoric acid. Distilled water was utilized throughout the experiments for solution preparation and glassware cleaning.

\section{Preparation of activated carbons}

In our study, we used (Sawi date palm pits) and the material was collected from pastry factory in (Shubra Al Khaimah). The date palm pits were washed with hot deionized water to remove dust and other impurities, and dried at $105^{\circ} \mathrm{C}$. Raw materials were ground into fine particles and sieved to a particle size of $(2 \mathrm{~mm})$. Phosphoric acid activated carbon samples were prepared by soaking date palm pits in $50 \mathrm{wt}$. \% analytical grade phosphoric acid at room temperature at different ratios of raw material to phosphoric acid (CP212, CP214 and CP124) for curing time two days for the first sample and four days for the second and third sample. The slurry was occasionally stirred, the solid was then separated and heated gradually in absence of air in a stainless steel reactor at a rate of heating $=10{ }^{\circ} \mathrm{C} / \mathrm{min}$ up to $550{ }^{\circ} \mathrm{C}$ and then maintained at that temperature for $3 \mathrm{~h}$. After cooling, the activated carbon mass was washed with distilled water till washing solution attained a pH value of 6.0 then the washed material was dried at $110{ }^{\circ} \mathrm{C}$ for $24 \mathrm{~h}$ and stored in clean dry bottles [9].

\section{Characterization methods}

\subsection{Determination of $\%$ ash contents, weight loss on drying, $\mathrm{pH}$ of the supernatant and} pHpzc

The ash content percentage fixed carbons were carried out on each sample of the activated carbon and the precursor. For each sample a crucible was placed in furnace at $650{ }^{\circ} \mathrm{C}$ for $1 \mathrm{~h}$, cooled down in a desiccator, and the weight of ignited crucible was recorded, $2.0 \mathrm{~g}$ sample of activated carbon was placed in a crucible and transferred into a muffle furnace at $650{ }^{\circ} \mathrm{C}$ for six hours. After heating, the crucible was allowed to cool to room temperature in desiccator. The percentage ash content was determined using Eq. (1) [10,11].

Where, $W_{f}$ is the weight of sample pulse crucible after firing, $W_{c}$ is the weight of empty crucible and $\mathrm{W}_{\mathrm{s}}$ is the weight of sample before firing.

The weight loss during drying was determined for the date palm pits and activated sample by weighting $0.5 \mathrm{~g}$ of the sample and heating for $24 \mathrm{~h}$ in oven at $110 \mathrm{C}^{0}$ until the weight of the sample became constant using Eq. (2). 
Where, $\mathrm{W}_{\mathrm{b}}$ and $\mathrm{W}_{\mathrm{a}}$ is the weight of sample before and after drying respectively

$\mathrm{pH}$ of the supernatant was determined by adding $0.5 \mathrm{gm}$ of adsorbent to $25 \mathrm{~mL}$ of deionized water and the mixture was shaking for $48 \mathrm{~h}$, the supernatant was then filtered to remove solid adsorbent and the $\mathrm{pH}$ of the supernatant was measured using Jenway $\mathrm{pH}$-meter. pHpzc of activated carbon was also measured as $50 \mathrm{~mL}$ of $0.01 \mathrm{M} \mathrm{NaCl}$ solutions was put into several closed Erlenmeyer flasks. The $\mathrm{pH}$ in each flask was adjusted to a value between 2 and 6 by adding $\mathrm{HCl}(0.01 \mathrm{M})$ or $\mathrm{NaOH}(0.01 \mathrm{M})$ solutions. We take $0.15 \mathrm{~g}$ from the sample and added them to each flask, the flasks were agitated for $48 \mathrm{~h}$, and the final $\mathrm{pH}$ was then measured. The $\mathrm{pHpzc}$ is the point where $\mathrm{pH}$ final $-\mathrm{pH}$ initial = zero [12].

\subsection{Scanning Electron Microscopy (SEM) analysis}

The surface morphology was obtained using Scanning Electron Microscope (Quanta 250 FEG) working at a high voltage of $15 \mathrm{kV}$. The samples were coated with gold by a gold sputtering device for clear visibility and conductivity. Thereafter, the coated sample was placed on the sample holder for analysis $[13,14]$.

\subsection{Surface area and pore size analysis}

The surface area and average pore size of samples were determined using a gas sorption analyzer. The adsorption-desorption isotherm of nitrogen was determined at its boiling point $196{ }^{\circ} \mathrm{C}$ by ASAP 2020 instrument. The samples were degassed under vacuum at $350{ }^{\circ} \mathrm{C}$ for $3 \mathrm{~h}$ prior to measurement. The nitrogen adsorption-desorption data were recorded at liquid nitrogen temperature of $-196{ }^{\circ} \mathrm{C}$. The adsorption equilibrium time was set at $60 \mathrm{~S}$. The Brunauer, Emmett and Teller (BET) method was used to calculate the surface area, using the data obtained from the $\mathrm{N}_{2}$ adsorption isotherm within the $\mathrm{P} / \mathrm{P}^{0}$ range of $0.05-0.30$, where $\mathrm{P}$ is the equilibrium pressure and $\mathrm{P}^{0}$ is the saturation pressure.

\subsection{Adsorption equilibrium studies}

Batch adsorption experiments were undertaken in a series of Erlenmeyer flasks containing 0.25g of ACS and equal volumes of methylene blue solutions at varying concentration (50-500 mg /L). The flasks were shaken in a thermostatic shaker at the desired temperature with shaking speed of $150 \mathrm{rpm}$ for $24 \mathrm{~h}$. The equilibrium concentrations of methylene blue in the supernatant were analyzed spectrophotometrically using (HPST uv/vis spectrophotometer) at $\lambda_{\max } 662 \mathrm{~nm}$. The effects contact time were studied with respectto the adsorption of MB byCP212, CP214 and CP124.The effect of temperature was studied by conducting a batch adsorption experiment at 25, 35, and $45^{\circ} \mathrm{Cfor} \mathrm{CP} 124$ as a selected sample.

\section{Results and Discussion}

\section{Characterization of precursor and activated carbon samples.}

Table 1: Ash content weight loss drying, pH of supernatant and pHpzc of samples.

\begin{tabular}{|c|c|c|c|c|}
\hline sample & $\begin{array}{c}\text { Percentage ash } \\
(\%)\end{array}$ & $\begin{array}{c}\text { Weight loss } \\
\text { drying (\%) }\end{array}$ & $\begin{array}{c}\text { pH of } \\
\text { supernatant }\end{array}$ & pHpzc \\
\hline DPP & 0.77 & 13.24 & 5.95 & 6.32 \\
\hline CP212 & 5.170 & 4.59 & 2.35 & 3.20 \\
\hline CP214 & 4.765 & 4.960 & 2.65 & 3.5 \\
\hline CP124 & 3.214 & 5.155 & 3.00 & 4.3 \\
\hline
\end{tabular}

Table 1 shows that ash content for DPP is $0.77 \%$ it is very low due to the higher amount of cellulose and lignin [15], while for modified AC it is in the range of 3.214-5.170\%. We can say that activating agent has the ability to dissolve apart of ash content; Moisture content is one of 
the factors that will influence adsorption capacity of activated carbon (AC). Moisture content in case of DPP was (13.24 \%) which is higher compared with that for activated samples and this may be related to the decomposition of polar cellulose and hemi cellulose during chemical activation at higher temperature in absence of air, while for sample activated by $\mathrm{H}_{3} \mathrm{PO}_{4}$ the weight loss during drying increase with increasing the percent of activating agent and curing time, This is a logical result of the higher surface area, The $\mathrm{pH}$ value of activated carbon sample is mainly based on the inorganic ingredients in the source material or added during manufacture. In this study, acidic $\mathrm{pH}$ values were obtained. This is due to phosphorus-containing compounds such as polyphosphates, which may form during impregnation [16].

\section{Scanning electron microscopy (SEM)}

Scanning electron microscopy images were taken to observe the surface topography of the sample. Basically, the pore structure of activated carbon was observed. The micrographs of activated carbon are shown in (Fig.1) which showed that chemically activated carbon sample have high porosity compared to date palm pits ( DPP ). This was because during carbonization process of raw material with phosphoric acid at high temperature $\left(550^{\circ} \mathrm{C}\right)$, most volatile matter was lost and thus created a system with advanced pore structure. Impregnation with phosphoric acid followed by the second carbonization dehydrated the cellulose material, resulting in weakening of the precursor structure and creation of pores. During chemical activation process, phosphoric acid was responsible for decomposition of organic material to release volatile matter and development of micro porous structure which could increase the adsorption capacity [17] Besides, we found that for the sample activated with phosphoric acid by increasing the percent of activating agent it minimizing the formation of tars and other liquids which could clog up the pores and inhibit the development of pores as clear in sampleCP124 [18]. The porosity created in the carbon structure was also resulted from phosphoric acid removal from carbon structure by intense washing

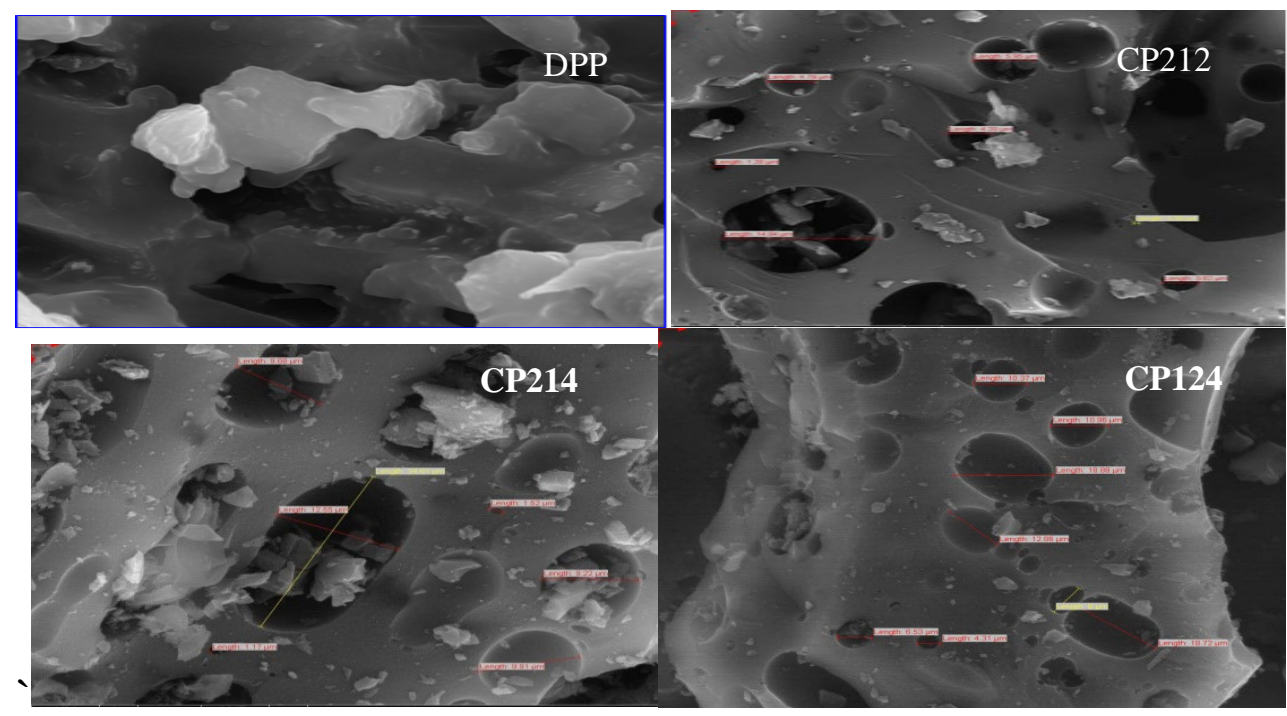

Fig. 1: SEM for (DDP) and activated carbons CP212, CP214 and CP124. 


\section{Surface area and pore structure.}

The BET surface area $\left(\mathrm{S}_{\mathrm{BET}}\right)$, external and mesopore surface area $\left(\mathrm{S}_{\mathrm{ext}+\mathrm{mes}}\right)$ and the mean pore radius $\left(\mathrm{r}^{-}\right)$of the activated carbons were determined by application of Brunauer-Emmett-Teller (BET) analysis software with the instrument. The BET surface area was determined by means of the standard BET equation applied in the relative pressure range from 0.06 to 0.30 [19]. The data are summarized in Table 2.

Table 2: Textural properties of the investigated carbons as determined from nitrogen adsorption at $-196^{\circ} \mathrm{C}$

\begin{tabular}{|c|c|c|c|c|c|c|}
\hline Adsorbents & $\mathrm{S}_{\mathrm{BET}}\left(\mathrm{m}^{2} / \mathrm{g}\right)$ & $\mathrm{C}_{\mathrm{BET}}$ & $\begin{array}{c}\mathrm{S}_{\text {ext+meso }} \\
\left(\mathrm{m}^{2} / \mathrm{g}\right)\end{array}$ & $\begin{array}{c}\mathrm{V}_{\mu} \\
\left(\mathrm{cm}^{3} / \mathrm{g}\right)\end{array}$ & $\begin{array}{c}\mathrm{V}_{\mathrm{P}} \\
\left(\mathrm{cm}^{3} / \mathrm{g}\right)\end{array}$ & $\begin{array}{c}\mathrm{r}^{-} \\
(\mathrm{nm})\end{array}$ \\
\hline DPP & 0 & 0 & 0 & 0 & 0 & 0 \\
\hline CP212 & 427.8 & -45.05 & 112.3 & 0.178 & 0.243 & 1.14 \\
\hline CP214 & 470.6 & -43.74 & 110.9 & 0.201 & 0.266 & 1.13 \\
\hline CP124 & 620.3 & -187 & 330.7 & 0.172 & 0.567 & 1.82 \\
\hline
\end{tabular}

We can conclude that: (i) the surface area for the date palm pits (DPP) is zero due to the absence of the activating agent. (ii) Activation with $\mathrm{H}_{3} \mathrm{PO}_{4}$ raise surface area, total pore volume, micropores volume and pore radius. The last results based on that activation of biomass based materials are dehydrating agents. These dehydrating agents penetrate deep into the biomass structure and cause the organic molecules to disintegrate into smaller molecules. After the release of these smaller molecules, tiny pores were created. Besides helping in the development of new pores or expansion of the pore, it also affects in enhancing the surface area. Normally, it was observed that micropores and mesopore formation results into a larger surface area of the activated carbons.(Fig.2) presents the nitrogen adsorption/desorption isotherms at $-196{ }^{\circ} \mathrm{C}$ for the investigated activated carbon sample. It is clear that all above sample give hysteresis loop, this hysteresis loop is usually attributed to thermodynamic or network effects or combination of two effects [20].

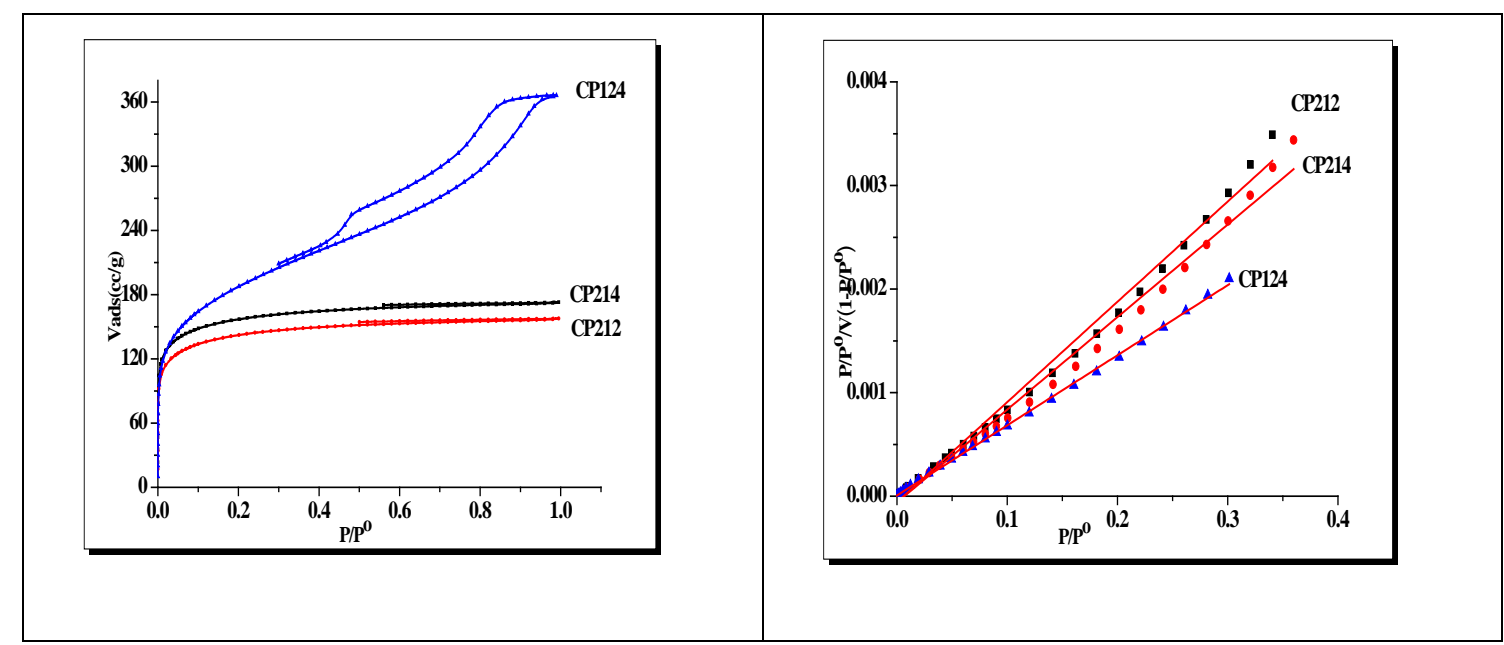

Fig. 2: Nitrogen adsorption isotherms and Linear BET plots of activated carbon sample at -196

${ }^{\circ} \mathrm{C}$ 


\section{Adsorption of Methylene blue.}

4.1 Effect of contact time on adsorption.

The adsorptions of the methylene blue by activated carbon (CP214 andCP124) were studied at various time intervals (0.25- $25 \mathrm{~h}$ ). (Fig .3) showed that the adsorption of methylene blue is fast in the initial stage by passing the time it will decrease till a constant value at about $15 \mathrm{~h}$ (equilibrium time). The fast adsorption at the initial stage occur due to the presence of high uncovered surface area and active sites on the adsorbent [21,22]. The slow adsorption of methylene blue by passing the time due to the small availability of uncovered surface area and fewer remaining active sites, resulting in lengthy time for adsorption to reach equilibrium of methylene blue [23].

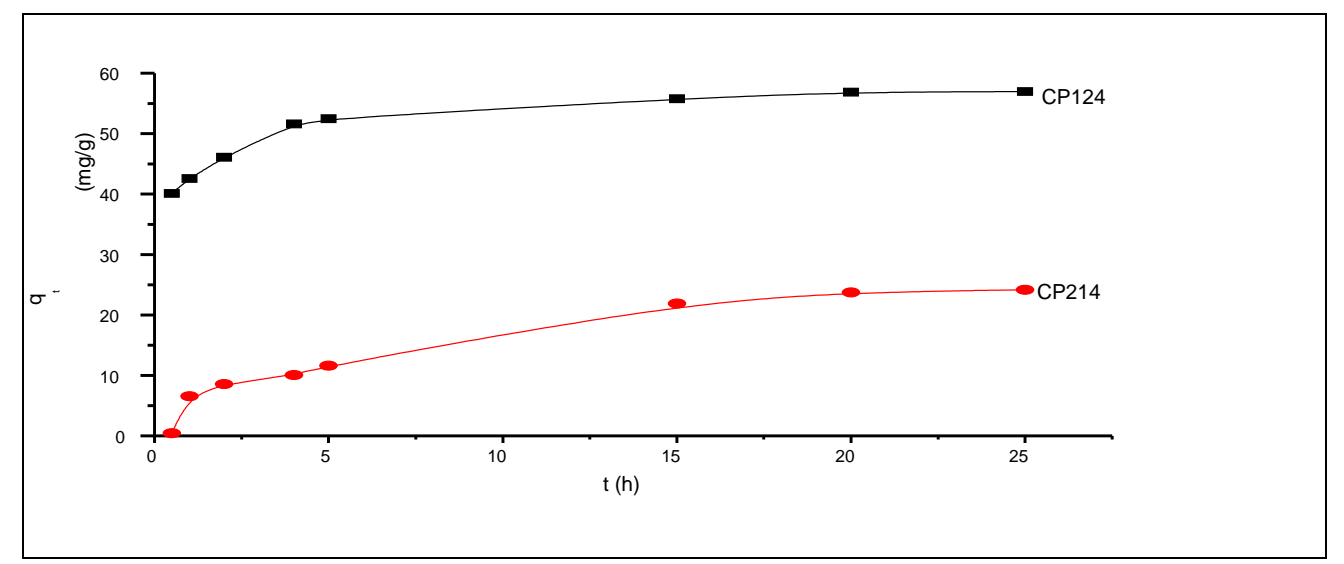

Fig. 3: Effect of contact time on removal of methylene blue onto CP214 and CP124

A kinetic study considers as method to give us information about the adsorption mechanism in our studies pseudo-first and pseudo-second order models were applied for CP214and CP124. The linearized form of the PFO can be expressed as

$\log \left(q_{e}-q_{t}\right)=\log q_{e}-\frac{K_{1}}{2} \cdot 303 t$

Where $\mathrm{q}_{\mathrm{e}}$ is the equilibrium adsorbed amount $(\mathrm{mg} / \mathrm{g}), \mathrm{q}_{\mathrm{t}}$ is the amount adsorbed in time $\mathrm{t}$ ( $\mathrm{mg} / \mathrm{g}), \mathrm{K}_{1}$ is the pseudo-first-order rate constant ( $\mathrm{g} / \mathrm{mg}$. $\mathrm{min}$ ) and $\mathrm{t}$ is the time in minute .The linearized form of the PSO can be expressed as

$\frac{t}{q_{t}}=\frac{1}{K_{2} q_{e}}+\frac{1}{q_{e}^{\sqrt{2}}} t$

Where $\mathrm{K}_{2}$ is the pseudo second order rate constant (g/mg. min)

(Fig. 4) depicts the application of linear pseudo-first-order and linear pseudo second order kinetics model. Upon analysis of Table 3 one can concluded that the adsorption follow pseudosecond order kinetics model based on: (i) Correlation coefficient $\mathrm{R}^{2}$ for PSO ranged between 0.9904 and 0.9943 indicating the good applicability of PSO linearized form. On the other hand, $\mathrm{R}^{2}$ for PFO is very low (ranged between 0.89107and 0.67129). (ii) Calculated $\mathrm{q}_{\mathrm{e}}(\mathrm{mg} / \mathrm{g})$ from PSO model are closer to $\mathrm{q}_{\mathrm{m}}(\mathrm{mg} / \mathrm{g})$ calculated from Langmuir adsorption model while that calculated from PFO is very high. (iii) $\mathrm{K}_{2}$ ranged between 0.0159 and 0.0513 indicating the 
higher rate of adsorption especially in case of CP124 which exhibit a sharp increase in adsorption at beginning time of adsorption as shown in Fig (3).
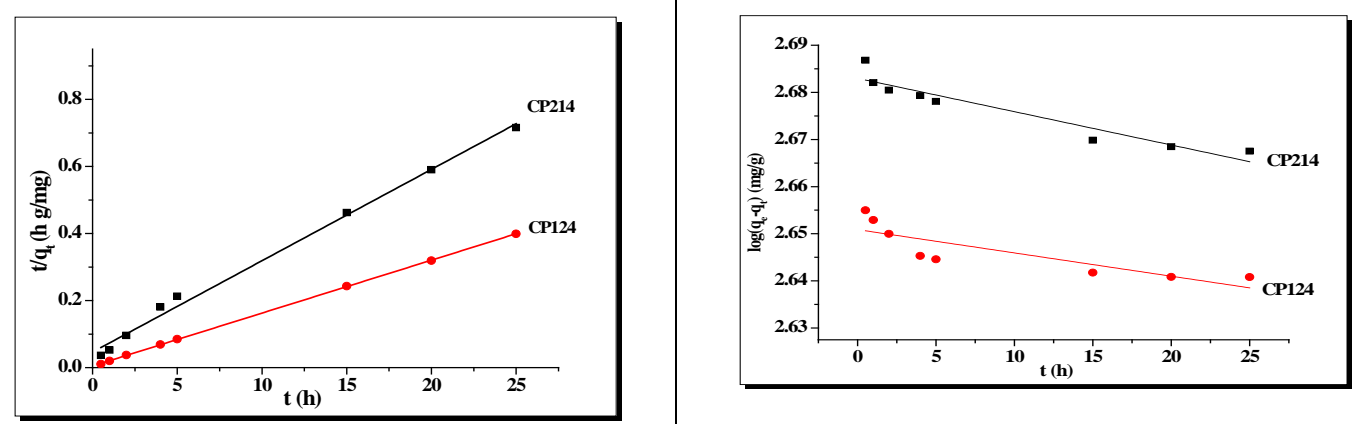

Fig. 4: Pseudo-first order and Pseudo-second order kinetic model for adsorption of MB onto activated carbon CP214 and CP124 samples.

Table 3: Parameter of pseudo-first-order and pseudo-second-order kinetics model for adsorption of methylene blue onto activated carbon samples

\begin{tabular}{|c|c|c|c|c|c|c|l|}
\hline \multicolumn{3}{|c|}{$\begin{array}{c}\text { Pseudo-second order kinetic } \\
\text { model }\end{array}$} & \multicolumn{3}{|c|}{ Pseudo-first order kinetic model } & \multirow{2}{*}{$\begin{array}{c}\text { qm } \\
(\mathrm{mg} / \mathrm{g})\end{array}$} & Sample \\
\hline $\mathrm{R}^{2}$ & $\begin{array}{c}\mathrm{K}_{2}(\mathrm{~g} / \\
\mathrm{mg} \mathrm{h})\end{array}$ & $\mathrm{q}_{\mathrm{e}}(\mathrm{mg} / \mathrm{g})$ & $\mathrm{R}^{2}$ & $\mathrm{~K}_{1}\left(\mathrm{~h}^{-1}\right)$ & $\mathrm{q}_{\mathrm{e}}(\mathrm{mg} / \mathrm{g})$ & & \\
\hline 0.9904 & 0.0159 & 36.764 & 0.89107 & $-16.28 \times 10-^{4}$ & 480.83 & 20 & $\mathrm{CP} 214$ \\
\hline 0.9943 & 0.0513 & 63.694 & 0.67129 & $-11.37 \times 10-^{4}$ & 477.50 & 81.36 & $\mathrm{CP} 124$ \\
\hline
\end{tabular}

\subsection{Adsorption isotherms.}

The purpose of carrying out the batch adsorption isotherm is to determine the best isotherm model for methylene blue adsorption by activated carbons and to determine the maximum adsorption capacity $\left(\mathrm{q}_{\max }\right)$. In this study we used Langmuir models [24] which describe the monolayer adsorption of the adsorbate onto the sorbent. The linear equation for this model is given by

$\frac{\mathbf{c}_{\mathrm{e}}}{\mathbf{q}_{\mathrm{e}}}=\frac{1}{\mathbf{b} \mathbf{q}_{\mathrm{m}}}+\frac{\mathbf{C}_{\mathrm{I}}}{\mathbf{q}_{\mathrm{e}}}$

Where $\mathrm{q}_{\mathrm{e}}$ is the amount adsorbed at equilibrium time $(\mathrm{mg} / \mathrm{g}), \mathrm{C}_{\mathrm{e}}$ is the equilibrium concentration of methylene blue (mg / L), $\mathrm{q}_{\mathrm{m}}$ is the maximum adsorption capacity ( $\mathrm{mg} / \mathrm{g}$ ), and b is known by Langmuir constant $(\mathrm{L} / \mathrm{mg})$ and it is related to the heat of adsorption. If we plot $\mathrm{C}_{\mathrm{e}} / \mathrm{q}_{\mathrm{e}}$ versus $C_{e}$ for methylene blue activated carbons, it will give a straight line with slope $=1 / q_{m}$ and an intercept $=1 / \mathrm{bq}_{\mathrm{m}}$, as shown in (Fig.5A). One of the essential characterizes of Langmuir isotherm can be expressed by a separation factor, $\mathrm{R}_{\mathrm{L}}$ : which is defined as showed in equation (6).

$\mathbf{R}_{\mathbf{L}}=\frac{1}{\mathbf{1}+\mathbf{b} \mathbf{I}_{\mathbf{0}}}$ 
Here, $C_{o}$ is the highest initial solute concentration. The $R_{L}$ value implies whether the adsorption is unfavorable $\left(R_{L}>1\right)$, linear $\left(R_{L}=1\right)$, favorable $\left(0<R_{L}<1\right)$, or irreversible $\left(\left(R_{L}=0\right)\right.$.

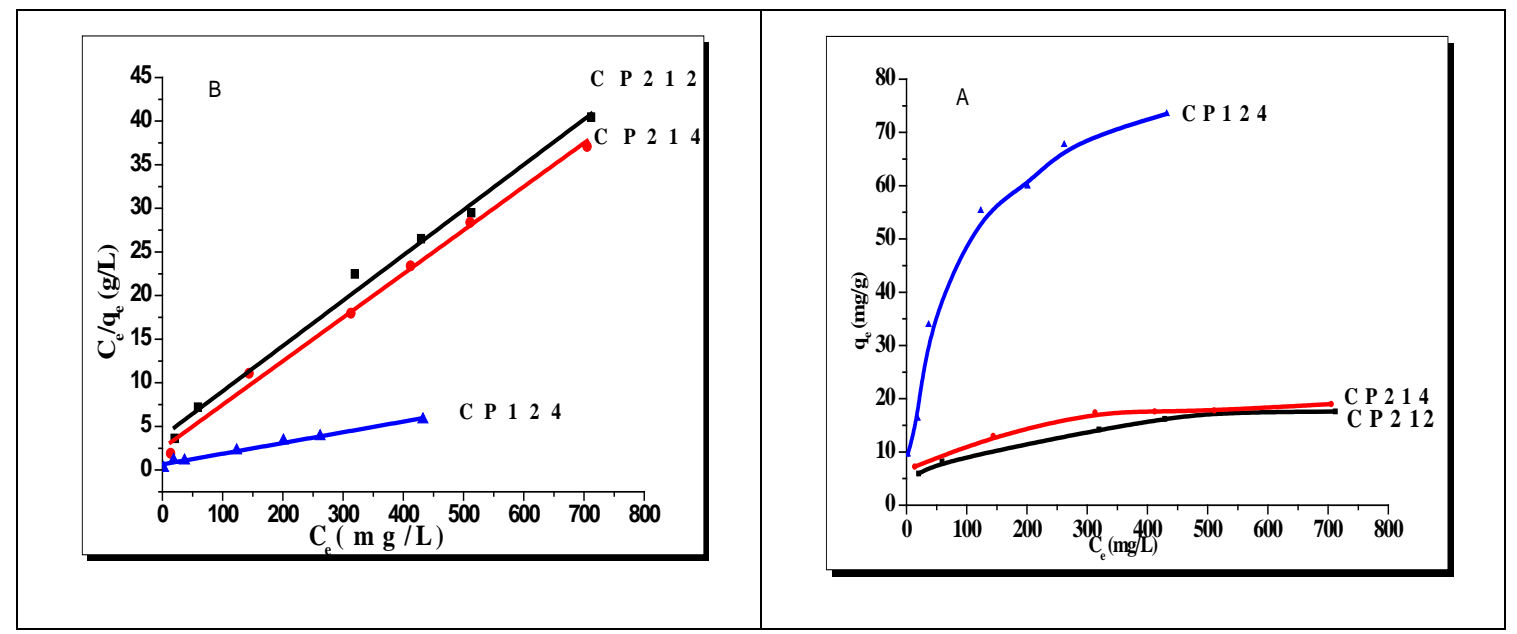

Fig. 5: Adsorption isotherms (A) and linear Langmuir equation of methylene blue onto activated carbon samples $(B)$.

Table 4: Langmuir parameter for adsorption of MB onto investigated carbon samples.

\begin{tabular}{|c|c|c|c|c|}
\hline \multicolumn{4}{|c|}{ Langmuir parameters } & \multirow[t]{2}{*}{ Sample } \\
\hline $\mathrm{R}_{\mathrm{L}}$ & $\mathrm{R}^{2}$ & $\mathrm{~b}(\mathrm{~L} / \mathrm{mg})$ & $\mathrm{q}_{\max }(\mathrm{mg} / \mathrm{g})$ & \\
\hline 0.0847 & 0.9909 & 0.0135 & 19.249 & CP212 \\
\hline 0.0585 & 0.9933 & 0.0201 & 20 & CP214 \\
\hline 0.0617 & 0.9808 & 0.019 & 81.366 & CP124 \\
\hline
\end{tabular}

From (Fig 5A) we observed that a very steep initial raise at the beginning of adsorption, this may be due to the fact that as initial concentration increases there are adsorption sites available for adsorption of methylene blue, thus enhancing the \% uptake [25]. Upon inspection of Table 4, (i) Correlation coefficient $\left(\mathrm{R}^{2}\right)$ ranged between 0.9808 and 0.9909 indicating the accepted applicability of Langmuir models as shown in (Fig 5B). (ii) $\mathrm{R}_{\mathrm{L}}$ value lies between 0 and 1 indicating that adsorption of methylene blue on activated carbon was favorable .It is clear that the $R_{L}$ values decrease with the increase in initial dye concentration, indicating that the adsorption was favorable at higher MB concentration. (iii) CP212 and CP214 approximately have the same value of $\mathrm{q}_{\mathrm{m}}$ due to there is no observable difference in surface area or surface chemistry, while by doubling amount of $\mathrm{H}_{3} \mathrm{PO}_{4}$ activating agent as in CP124 sample there is observable increase in $\mathrm{q}_{\mathrm{m}}$ by about 4 times based on increasing surface area by about $150 \mathrm{~m}^{2} / \mathrm{g}$.

\subsection{Effect of temperature and thermodynamic study}

The effect of temperature on the removal of $\mathrm{MB}$ in aqueous was studied by varying the temperature between 25, 35 and $45^{\circ} \mathrm{C}$. The data presented in Fig 6 and it showed that adsorption of MB on CP124, activated carbon sample increase with raising temperature from 25 to $45{ }^{\circ} \mathrm{C}$, due to the enlargement of pore size or creation of some new active sites on the surface of adsorbent due to rupture of bond. These also lead to enhancement the transformation of MB from the bulk of solution to the surface 


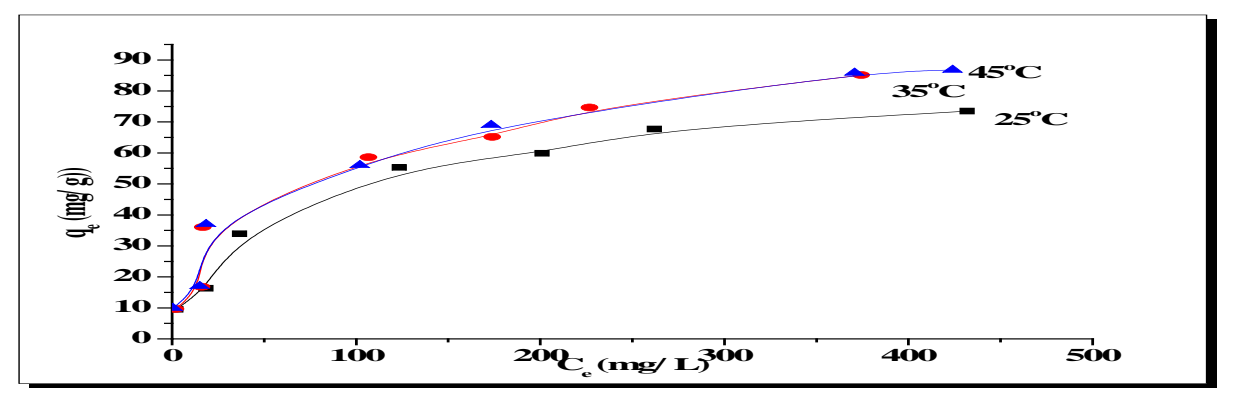

Fig. 6: Adsorption of methylene blue on CP124 activated carbon sample at 25, 35 and $45^{\circ} \mathrm{C}$.

Thermodynamic parameters were calculated for CP124 sample, to explain the nature of adsorption process on the surface and within the pores of activated carbons. The distribution coefficient, Entropy change, and Gibbs free energy change of the adsorption process is related to the equilibrium constant by the classic Van’t Hoff equation

$$
\mathbf{K}_{\mathbf{d}}=\frac{\mathbf{C}_{\mathrm{s}}}{\mathbf{l}_{\mathrm{e}}}
$$

Where $K_{d}$ is the distribution coefficient for the adsorption, $C_{s}$ is the surface concentration of MB and $\mathrm{C}_{e}$ the equilibrium concentration. According to thermodynamics, the Gibbs free energy change is also related to the entropy change and heat of adsorption at constant temperature by the following equation:

$\Delta \mathbf{G}^{\circ}=\Delta \mathbf{H}^{\circ}-\mathbf{T} \Delta \mathbf{I}^{\circ}$

$\Delta \mathbf{G}^{*}=-\mathrm{RT} \ln \mathrm{K}_{\mathrm{d}}$

Where, $\mathrm{R}$ is the universal gas constant $\left(8.314 \times 10^{-3} \mathrm{~kJ} \mathrm{~K}^{-1} \mathrm{~mol}^{-1}\right)$, T is temperature in $\mathrm{K} . \Delta \mathrm{G}^{\circ}$ is the free energy change $\left(\mathrm{kJ} \mathrm{mol}^{-1}\right), \Delta \mathrm{H}^{\mathrm{o}}$ is the change in enthalpy $\left(\mathrm{kJ} \mathrm{mol}^{-1}\right), \Delta \mathrm{S}^{\mathrm{o}}$ is the entropy change $\left(\mathrm{kJ} \mathrm{mol}^{-1} \mathrm{~K}^{-1}\right.$ ), Thus $\Delta \mathrm{H}^{0}$ and $\Delta \mathrm{S}^{0}$ can be determined by the slope and intercept. The value of $\Delta \mathrm{S}^{\circ}, \Delta \mathrm{H}^{\circ}$ and $\Delta \mathrm{G}^{\circ}$, are showed in Table 5. The negative values of free energy change mean spontaneous process with a high affinity of the adsorbate to the surface of adsorbent. The positive value of enthalpy change and standard entropy indicated spontaneous and endothermic nature of adsorption process.

Table 5: Thermodynamics parameter for adsorption of MB onto CP124

\begin{tabular}{|c|c|c|c|c|c|}
\hline \multicolumn{3}{|c|}{$\begin{array}{c}\Delta \mathrm{G} \\
\left.(\mathrm{kJ} \mathrm{mol})^{-1}\right)\end{array}$} & $\begin{array}{c}\Delta \mathrm{H}^{\mathrm{o}} \\
\left(\mathrm{kJ} \mathrm{mol}^{-1}\right)\end{array}$ & $\begin{array}{c}\Delta \mathrm{S}^{\mathrm{o}} \\
\left(\mathrm{kJ} \mathrm{mol}^{-1} \mathrm{~K}^{-1}\right)\end{array}$ & Sample \\
\hline $318 \mathrm{~K}$ & $308 \mathrm{~K}$ & $298 \mathrm{~K}$ & & 0.081 & CP124 \\
\hline-5.056 & -4.246 & -3.436 & 20.702 & 082 & \\
\hline
\end{tabular}

\section{Conclusions}

Three activated carbons were prepared from (DPP) using activating agents: $\mathrm{H}_{3} \mathrm{PO}_{4}$, ash content, nitrogen adsorption, SEM and $\mathrm{pH}_{\mathrm{PZC}}$. $\mathrm{S}_{\mathrm{BET}}$ ranged between 427.8 and $620.3 \mathrm{~m}^{2} / \mathrm{g}$. The optimum condition for removal of $\mathrm{MB}$ was confirmed at $\mathrm{pH} 7$, equilibrium time $24 \mathrm{~h}$ and increased with temperature. Maximum adsorption capacities for the three adsorbents were found to be 19.2, 20, 
and $80 \mathrm{mg} / \mathrm{g}$ for CP212, CP214 and CP124, respectively at $25{ }^{\circ} \mathrm{C}$. The adsorption of $\mathrm{MB}$ on the prepared activated carbons follow pseudo-second order kinetic model with correlation coefficients reached to 0.9933. Thermodynamic measurements showed spontaneous and endothermic nature of adsorption process.

\section{References}

[1] M. Alkan, O. Demirbas, S. Celikc, M. Dogan, Sorption of acid red 57 from aqueous solutions ontosepiolite, J Hazard. Mater. 116 (2004) 135-145. https://doi.org/10.1016/j.jhazmat.2004.08.003

[2] K. Turhan, S.A. Ozturkcan, Decolorization and Degradation of Reactive Dye in Aqueous Solution by Ozonation in a Semi-batch Bubble Column Reactor, Water, Air, Soil Pollut. 224 (2012) 1353. https://doi.org/10.1007/s11270-012-1353-8

[3] T. Liu et al., Biointerfaces Adsorption of methylene blue from aqueous solution by graphene, Colloids Surfaces Biointerfaces 90 (2012) 197-203.

https://doi.org/10.1016/j.colsurfb.2011.10.019

[4]P. Saha, R. Das Mishra, R. Husk, Adsorption of safranin onto chemically modified rice husk in a upward flow packed bed reacto: artificial neural network modeling, Biotechnol. Adv. 44, (2012) 7579-7583.

[5] T.A. Khan, S. Sharma I. Ali, Adsorption of Rhodamine B dye from aqueous solution onto acidactivated mango (Magnifera indica) leaf powder: Equilibrium, kinetic and thermodynamic studies, J.Toxicol. Environ. Heal. Sci. 3, (2011) 286-297

[6] F. Rodriguez-Reinoso, M. Molina-Sabio, Activated carbons from lignocellulosic materials by chemical and/or physical activation: an overview, Carbon 30 (1992) 1111-1118. https://doi.org/10.1016/0008-6223(92)90143-k

[7] C.A. Toles, W.E. Marshall, L. HWartelle, A. McAloon, A Steam-orcarbon dioxide-activated carbons from almond shells: physical, chemical and adsorptive properties and estimated cost of production. Bioresour Technol 75-3 (2000) 197-203. https://doi.org/10.1016/s09608524(00)00058-4

[8] N. M. Haimour, S. Emeish, Utilization of date stones for production of activated carbon using phosphoric acid, Waste Manag 26 (2006) 651-660. https://doi.org/10.1016/j.wasman.2005.08.004

[9] A. M. Youssef, M. N Alaya, N. Nawar, Adsorption properties of activated carbon obtained from polymer wastes, Adsorb. Sci. Technol 11 (1994) 225. https://doi.org/10.1177/026361749401100405

[10] E.O. Odebunmi, O.F. Okeola, Preparation and characterization of activated carbon from Waste Material, J. Chem. Soc. Nigeria 26-2 (2001) 149- 155.

[11] F.A. Adekola, H.I. Adekoge, Adsorption of Blue Dye on activated carbon from rice husk, coconut shell and coconut coirpith, Ife journal of Science, Nigeria 7(1) (2005) 151 - 157. https://doi.org/10.4314/ijs.v7i1.32169 
[12] A.F. Hassan, A.M. Youssef, P. Priecel, Removal of deltamethrin insecticide over highly porous activated carbon prepared from pistachio Nutshells, Carbon Lett 14 (2013) 234-242. https://doi.org/10.5714/cl.2013.14.4.234

[13] W.J. Liu, F.X. Zeng, H. Jiang, X. S. Zhang, Preparation of high adsorption capacity biochars from waste biomass" Bioresource technology 102(17) (2011) 8247-8252.

https://doi.org/10.1016/j.biortech.2011.06.014

[14] L. Wang, X. Wang, B. Zou, X. Ma, Y. Qu, C. Rong, Y. Li, Y. Su, Z. Wang, Preparation of carbon black from rice husk by hydrolysis, carbonization and pyrolysis" Bioresource technology 102(17) (2011) 8220-8224. https://doi.org/10.1016/j.biortech.2011.05.079

[15] M.M. Yeganeh, T. Kaghazchi, M. Soleimani, Effect of raw materials on properties of activated carbons, Chem Eng Technol 29 (2006) 1247. https://doi.org/10.1002/ceat.200500298

[16] A.M Puziy, O.I. Poddubnaya, A. Martinez-Alonso, F.Suarez-Garcia, J.M.D Tascon, Synthetic carbons activated with phosphoric acid I. Surface chemistry and ion binding properties, Carbon 40 (2002) 1493-1505. https://doi.org/10.1016/s0008-6223(01)00317-7

[17] R. Malik, D. S. Ramteke, S. R. Wate, Adsorption of malachite green on groundnut shell waste based powdered activated carbon, Waste management 27-9 (2007) 1129-1138. https://doi.org/10.1016/j.wasman.2006.06.009

[18] W.B. Wan Nik, M.M. Rahman, A.M. Yusof, F.N. Ani, C.N. Che Adnan, Production of activated carbon from palm oil shell waste and its adsorption characteristics, in Proceedings of the 1st International Conference on Natural Resources, Engineering and Technology (2006) 646654.

[19] M. Aroua, S. Leong, L. Teo, W. Daud, Real time determination of kinetics of adsorption of lead (II) onto shell based activated carbon using ion selection electrode" Bioresour. Technol. 99 (2008) 5786-5792. https://doi.org/10.1016/j.biortech.2007.10.010

[20] F. Rouquerol, J. Rouquerol, K.S.W. Sing, Adsorption by powders and porous solid, Academic press, San Diego, 1999. https://doi.org/10.1016/b978-012598920-6/50006-3

[21] Y. Wu, S. Zhang, X. Guo, H. Huang, Adsorption of chromium (III) on lignin, Bioresour Technol 99 (2008) 7709.

[22] M.K. Aroua, S.P.P. Leong, L.Y. Teo, C.Y. Yin, W.M.A.W. Daud, Real time determination of kinetics of adsorption of lead (II) onto palm shell-based activated carbon using ion selective electrode Bioresour Technol. 99 (2008) 5786. https://doi.org/10.1016/j.biortech.2007.10.010

[23] Y. Li, Q. Du, X. Wang, P. Zhang, D. Wang, Z. Wang, Y. Xia, Removal of lead from aqueous solution by activated carbon prepared from Enteromorphaprolifera by zinc chloride activation, J Hazard Mater 183 (2010) 583-589. https://doi.org/10.1016/j.jhazmat.2010.07.063

[24] I. Langumir, The adsorption of gases on plane surface of glass, mica and platinum, J. Am. Chem. Soc 40 (1918) 1361-1403. https://doi.org/10.1021/ja02242a004

[25] R. Aravindhan, N.N. Fathima, J.R. Rao, B.U. Nair, Equilibrium and thermodynamic studies on the removal of basic black dye using calcium alginate beads, Colloids Surf A 299 (2007) 232. https://doi.org/10.1016/j.colsurfa.2006.11.045 